\title{
Influence of Long-term Annealing and Hot Bending on Creep of P92 Pipe
}

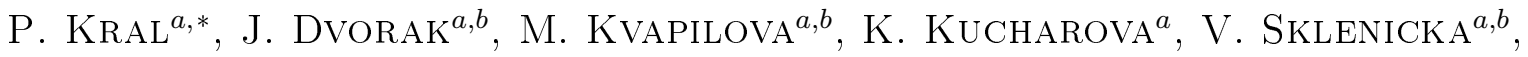 \\ M. SvOBODOVA ${ }^{c}$ AND J. CMAKAL ${ }^{c}$ \\ ${ }^{a}$ Institute of Physics of Materials, ASCR, Zizkova 22, 61662 Brno, Czech Republic \\ ${ }^{b}$ CEITEC-IPM, Institute of Physics of Materials, ASCR, 61662 Brno, CR \\ ${ }^{c}$ UJP PRAHA, a.s., 15610 Prague-Zbraslav, Czech Republic
}

\begin{abstract}
This work is focused on the creep behaviour of the thick-walled hot bended P92 pipe, with an outer diameter of $350 \mathrm{~mm}$ and wall thickness of $39 \mathrm{~mm}$, in its different parts, namely in straight parts and bends. Selected creep specimens machined from axial section of pipe were thermally aged at $650{ }^{\circ} \mathrm{C}$ to simulate microstructure degradation typical for long-term service conditions. Subsequent tensile creep tests at constant load were performed at $600{ }^{\circ} \mathrm{C}$ under $140 \mathrm{MPa}$ and creep behaviour of various structure states was compared. Microstructure was investigated by scanning electron microscopy equipped with electron backscatter diffraction. It was found that ageing at $650{ }^{\circ} \mathrm{C}$ for $10^{4} \mathrm{~h}$ caused the significant reduction of creep resistance down to about $10 \%$ of initial state and an additional slight reduction of creep resistance after longer ageing for $2 \times 10^{4} \mathrm{~h}$. Further, creep behaviour was significantly influenced by specimen position in the extrados and intrados parts of bends. Microstructure investigation revealed that long-term annealing has negligible effect on high-angle grain boundary spacing and misorientation. By contrast, creep deformation of long-term annealed specimens led to significant decreasing in high-angle grain boundary spacing and caused a change in the misorientation distribution of boundaries.
\end{abstract}

DOI: 10.12693 /APhysPolA.128.543

PACS: 81.05.-t, 81.40.-z, 62.20.Hg, 68.37.Hk

\section{Introduction}

The creep resistance of $9 \%$ chromium steels after longterm service is significantly reduced by recovery of the tempered martensite, coarsening of precipitates and evolution of new phases consuming $\mathrm{W}$ and $\mathrm{Mo}$ from the matrix or MX particles ( $\mathrm{Z}$ phase) [1-5]. Therefore, the deeper understanding to the microstructure stability of P92 steel is a critical factor for reliable prediction of creep life of high temperature components under service operation conditions of the power plants.

The coarsening resistant microstructure contains not only particles restricting the movement of boundaries but also low energy boundaries such as low-angle grain boundaries (LAGBs) and low energy martensite lath boundaries. The classical transformation models $[6,7]$ predict martensite lath boundaries as low-energy $\sum 3$ twins. It was found that boundary misorientations measured in creep resistant martensitic 9-12\% Cr steel using electron backscatter diffraction (EBSD) technique exhibit small deviations from classical models for austenitemartensite transformations [8]. Thus, it is reasonable to expect that coarsening of existing and the formation of new phases during long-term creep exposure are an indicator for a decrease of microstructure stability and creep resistance. The martensitic creep resistant P92 steel is an important structural material for key high temperature components of steam power plants such as tubes and

${ }^{*}$ corresponding author; e-mail: pkral@ipm.cz pipes. The steam pipelines system consists of straight tubes and bends which work at high temperature and under pressure. The resistance and safety of pipe system are given by component with the lowest lifetime. The aim of present work is to study of influence degraded microstructures formed during long-term annealing on creep behaviour of P92 steel and investigation of creep behaviour of P92 steel in bends and straight pipes.

\section{Experimental materials and procedures}

The experimental material used in present investigation was P92 steel. Its chemical composition (wt\%) was as follows: $0.11 \mathrm{C}, 8.58 \mathrm{Cr}, 0.33 \mathrm{Mo}, 1.67 \mathrm{~W}$, $0.37 \mathrm{Si}, 0.48 \mathrm{Mn}, 0.23 \mathrm{~V}, 0.06 \mathrm{Nb}, 0.013 \mathrm{P}, 0.037 \mathrm{~N}, 0.005 \mathrm{~S}$, $0.0015 \mathrm{~B}, 0.017 \mathrm{Al}$. The P92 steel pipe of dimensions OD $350 \mathrm{~mm} \times$ WT $39 \mathrm{~mm}$ (Productos Tubulares, s.a.u. Spain) was normalized at $1050^{\circ} \mathrm{C} / 60 \mathrm{~min} /$ air and tempered at $740^{\circ} \mathrm{C} / 140 \mathrm{~min} /$ air. The bends were manufactured by hot bending at $920-960{ }^{\circ} \mathrm{C}$ using bending rate $7 \mathrm{~mm} / \mathrm{min}$. After hot bending the pipe was normalized at $1050{ }^{\circ} \mathrm{C} / 60 \mathrm{~min} /$ air and tempered at $775^{\circ} \mathrm{C} / 140 \mathrm{~min} /$ air after hot bending [9]. The P92 steel pipe in as-received state was aged at $650^{\circ} \mathrm{C}$ for $10^{4} \mathrm{~h}$ and/or $2 \times 10^{4} \mathrm{~h}$ in order to obtain degraded experimental material. Tensile flat specimens were machined from different positions of the bend (intrados and extrados) and also from the unbent portion of the pipe.

Constant load tensile creep tests of initial and degraded states were conducted at $600^{\circ} \mathrm{C}$ and $140 \mathrm{MPa}$. Microstructure investigations were performed using scanning electron microscope Tescan Lyra 3 equipped with 
NordlysNano EBSD detector operating at an accelerating voltage of $20 \mathrm{kV}$ with specimen tilted at $70^{\circ}$. The EBSD analyses of gauge length (area of uniform deformation) and necking area of specimens were performed in the section parallel to the applied stress direction. The step size $200 \mathrm{~nm}$ for EBSD maps was selected with respect to interboundary spacing. The EBSD data were analyzed using HKL Channel 5 software developed by Oxford Instruments. The high-angle grain boundaries (HAGBs) were characterized as boundaries with misorientation angle $\theta \geq 15^{\circ}$ and low-angle grain boundaries (LAGBs) as boundaries with $\theta<15^{\circ}$. Standard intercepts counting of LAGBs and HAGBs was carried out along tests lines. The value of interboundary spacing was determined as the arithmetic mean of results in two perpendicular directions (horizontal, vertical).

\section{Results and discussion}

\subsection{Creep behaviour}

Creep results summarized in the Table show that the highest creep resistance is exhibited by material in the initial (as-received) state. The Table demonstrates that the isothermal ageing led to the significant reduction of creep resistance down to about $10 \%$ of that for an initial state after $10^{4} \mathrm{~h}$ and further slight reduction of creep resistance followed after prolonged ageing for $2 \times 10^{4} \mathrm{~h}$.

TABLE

Creep results for initial state, isothermal aged states of straight pipe and bend.

\begin{tabular}{|c|c|c|c|c|c|}
\hline \multicolumn{2}{|c|}{$\begin{array}{c}\text { P92 steel } \\
600^{\circ} \mathrm{C} / 140 \mathrm{MPa}\end{array}$} & $t_{\mathrm{f}}[\mathrm{h}]$ & $\varepsilon_{\mathrm{f}}[\%]$ & $\begin{array}{c}\varepsilon_{\mathrm{CRmin}} \\
{[\%]}\end{array}$ & $\Psi[\%]$ \\
\hline \multicolumn{2}{|c|}{ initial state - straight pipe } & 13787 & 6.9 & $3^{*}$ & 12.5 \\
\hline \multirow{3}{*}{$\begin{array}{c}\text { I. ageing } \\
650^{\circ} \mathrm{C} / 10^{4} \mathrm{~h}\end{array}$} & straight pipe & 1561 & 21.2 & 3 & 77.5 \\
\hline & extrados & 830 & 19.6 & 2.5 & 82.9 \\
\hline & intrados & 698 & 23 & 2.5 & 82.7 \\
\hline \multicolumn{2}{|c|}{$\begin{array}{c}\text { IA } 650^{\circ} \mathrm{C} / 2 \times 10^{4} \mathrm{~h} \\
\text { straight pipe }\end{array}$} & 803 & 21.8 & 2.5 & 83.2 \\
\hline
\end{tabular}

${ }^{*}$ creep $600{ }^{\circ} \mathrm{C} / 150 \mathrm{MPa}$.

The creep results also show that creep strain to fracture significantly increases after isothermal ageing. However, strain measured at the minimum creep rate $\left(\varepsilon_{\mathrm{CRmin}}\right)$ exhibited significantly lower (in the case of aged states) values in comparison with creep strain to fracture $\varepsilon_{f}$. It means that large deformation of aged specimens processed by isothermal ageing is localized in the necking area. This can be supported by increasing value of reduction of area $(\Psi)$ after isothermal ageing. The similar values of $\varepsilon_{\mathrm{CRmin}}$ may show that deformation resistance of different states is more or less similar and further increasing deformation influences detrimental creep processes leading to final fracture. The further decrease of creep resistance with prolonged time of isothermal ageing may be connected with coarsening of subgrain and/or precipitates and formation of new phases [1-5]. The creep results demonstrate that extrados of bend processed by isothermal ageing at $650{ }^{\circ} \mathrm{C} / 10^{4} \mathrm{~h}$ exhibited similar creep resistance as the state after ageing at $650^{\circ} \mathrm{C} / 2 \times 10^{4} \mathrm{~h}$. Intrados exhibited even lower creep resistance. The differences in the creep properties of straight pipe and bends are more probably caused by different processing history of these components initializing the microstructure weakening in the bends.

\subsection{Microstructure observations}

Figure 1 shows the influence of long-term isothermal ageing on interboundary spacing. It was observed that long-term isothermal ageing at $650{ }^{\circ} \mathrm{C}$ led to the nonsignificant growth of LAGBs and HAGBs spacing. Figure 2 shows that creep exposure of initial state caused slight changes in the LAGBs spacing both in the gauge length and in the area near to the fracture. Similar results were observed also in other works $[2,4,8,10]$ devoted to creep behaviour of initial state and stability of microstructure during isothermal ageing. It was reported that isothermal ageing has negligible effect on subgrain growth by contrast to subgrain significant growth during creep exposure.

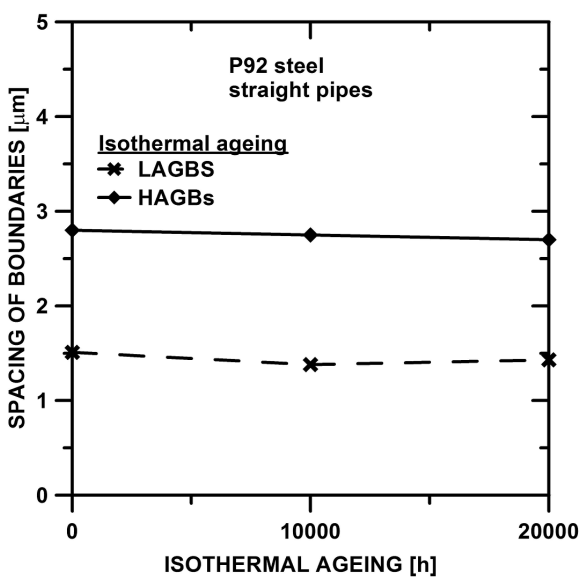

Fig. 1. Interboundary spacing in the straight pipes of P92 steel processed by long-term isothermal ageing.

However, in the present work it was also observed that additional creep loading caused coarsening of LAGBs and also HAGBs spacing in the gauge length of specimens processed by long-term isothermal ageing. Nevertheless opposite tendency was found in the necking area of isothermally aged specimens. Figure 2 demonstrates that LAGBs and HAGBs spacing after creep testing significantly decreases with increase of ageing time in the necking area.

The misorientation distribution measured in the microstructure of initial state and aged one is shown in Fig. 3. One can see that the misorientation distributions for all states are more or less similar. The analysis of the misorientation angles revealed two peak distributions. The first main group of boundaries is formed by LAGBs $\left(\theta<15^{\circ}\right)$ and the second by HAGBs $(\theta \lesssim$ $\left.50-61^{\circ}\right)$. The HAGBs exhibit preferential misorientations near $\sum 3\left(111 / 60^{\circ}\right)$, predicted by classical transformation models of the Kurdjumov-Sachs (K-S) [6] 


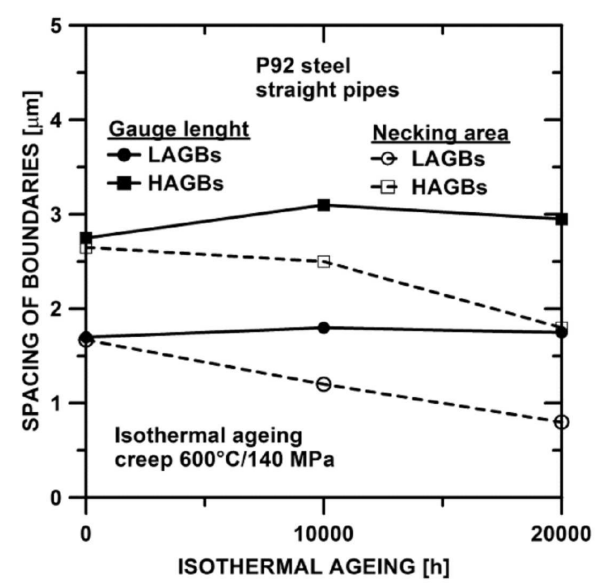

Fig. 2. Influence of long-term isothermal ageing on interboundary spacing in the straight pipes of P92 steel after creep exposure.

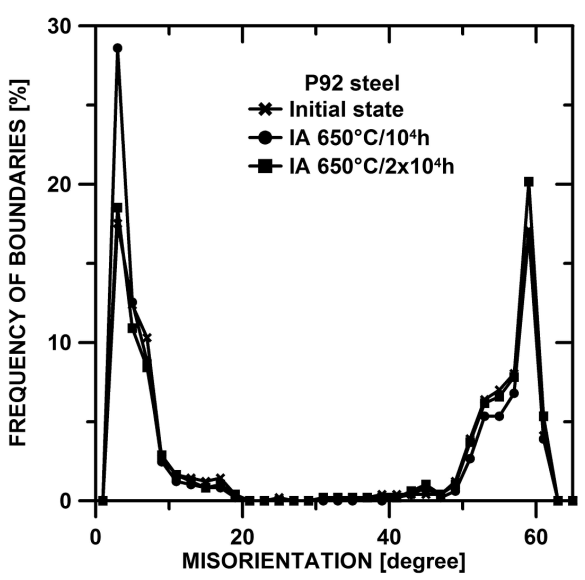

Fig. 3. Frequency of boundaries in the microstructure of initial and isothermal aged states.

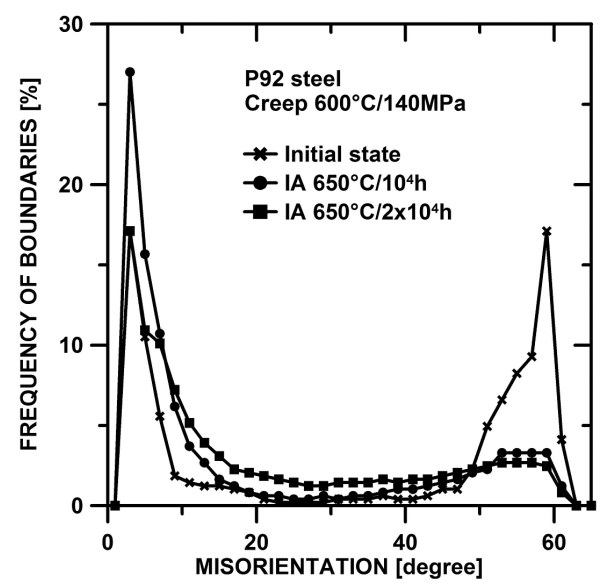

Fig. 4. Frequency of boundaries in the microstructure of initial and isothermal aged states after creep exposure. and Nishiyama-Wassermann (N-M) [7] as martensite lath boundaries. These models also predict that no lath boundaries with misorientations between $21-47^{\circ}$ are formed.

Figure 4 shows the misorientation distributions measured in the microstructure of initial and isothermally aged states situated near the fracture. It was observed that the concentration of plastic deformation in the necking area of isothermally aged specimens caused significant reduction of HAGBs $\left(\theta \lesssim 50-61^{\circ}\right)$, in particular preferential misorientations near $\sum 3\left(111 / 60^{\circ}\right)$ predicted as martensite lath boundaries. Nevertheless initial state retained two peak distribution of misorientation in the fracture area. It is caused by higher stability of martensitic structure and lower concentration of plastic deformation in the fracture region in comparison with isothermally aged specimens.

The coarsening in the gauge length and the reduction of LAGB and HAGB spacing in the necking area of specimens processed by isothermal ageing indicates that creep deformation has significant influence on the stability of martensitic structure. Changes in misorientation distribution also revealed that creep deformation has significant effect on frequency of boundaries predicted as martensite ones. It was reported that thermal ageing for $10^{4} \mathrm{~h}$ led to the formation of the Laves phase $[11,12]$ and to a decrease of creep resistance of $9 \%$ Cr steels [10]. In the present work was observed that the isothermal ageing (formation of the Laves phase) has only slight influence on stability of martensitic structure during isothermal ageing at $650^{\circ} \mathrm{C}$. Nevertheless, isothermal ageing leads to the significant decrease of creep resistance. Thus, it can be suggested that the Laves phase formation weakens stability of martensitic structure by decrease of $W$ and Mo contents in solid solution. The decrease of $\mathrm{W}$ and Mo in the solid solution leads to the higher mobility of boundaries because pinning effect becomes less effective. The microstructure results show that in the necking area dynamic recrystallization probably occurred which led to the reduction of HAGB spacing and to significant decrease of boundaries predicted as martensitic boundaries. The pinning effect can be also influenced by changes in MX carbonitrides which precipitate only during tempering. These precipitates are very stable against coarsening at temperature below $650^{\circ} \mathrm{C}[13,14]$ for exposure time lower that $10^{5} \mathrm{~h}$. From this reason it can be speculated about formation of the Laves phase having the largest influence on stability of martensitic structure during creep deformation.

The investigation of microstructure in the extrados and intrados parts of the bends treated by isothermal ageing at $650^{\circ} \mathrm{C} / 10^{4} \mathrm{~h}$ (Figs. 5, 6) showed the reduction in HAGB spacing in comparison with HAGB spacing measured in the straight part of pipe (Fig. 1). In the gauge length of specimens manufactured from extrados and intrados parts of the bends a significant coarsening of both HAGB and LAGB was observed in comparison with observed microstructure of isothermally aged 
states (Figs. 5, 6). Nevertheless, slight differences in the interboundary spacing were observed between the gauge length of the straight pipe and extrados/intrados parts of the bend.

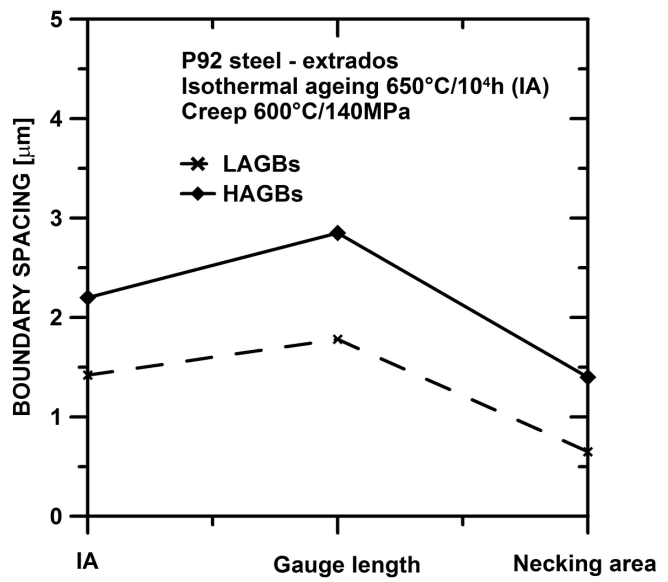

Fig. 5. Interboundary spacing in the extrados part of bend after isothermal ageing at $650^{\circ} \mathrm{C} / 10^{4} \mathrm{~h}$ and subsequently tested at $600{ }^{\circ} \mathrm{C}$.

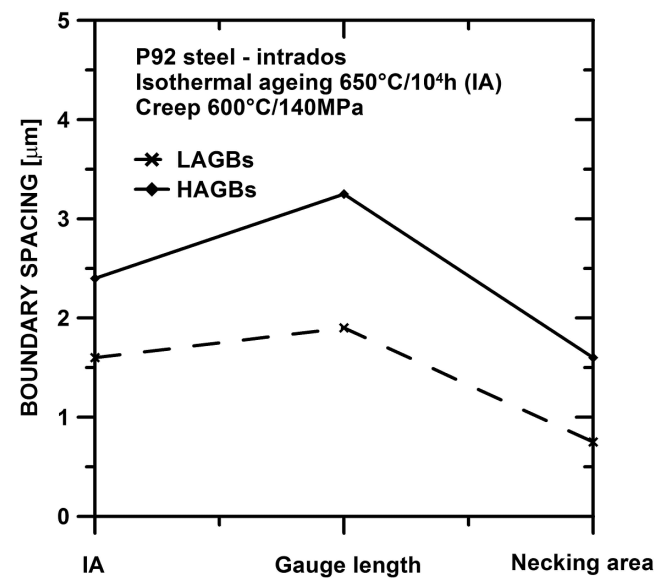

Fig. 6. As in Fig. 5, but for for the intrados part.

Further, significant decrease of LAGB and HAGB spacing was found in the necking area of extrados and intrados parts in comparison with the gauge length of the same specimens and isothermally aged state. The interboundary spacing measured in the necking area of extrados and intrados of bend was also significantly lower in the comparison with the interboundary spacing measured in the necking area of straight pipe isothermally aged for $10^{4} \mathrm{~h}$ (Figs. 5, 6).

Figures 7 and 8 show that misorientation measured in the extrados and intrados of bend after isothermal ageing, in the gauge length and necking area exhibited similar distribution. The misorientation distribution measured in the microstructure after isothermal ageing and in the gauge length shows two groups of boundaries predicted by transformation models of $\mathrm{K}-\mathrm{S}[6]$ and $\mathrm{N}-\mathrm{W}[7]$. The misorientation distributions demonstrate that in the

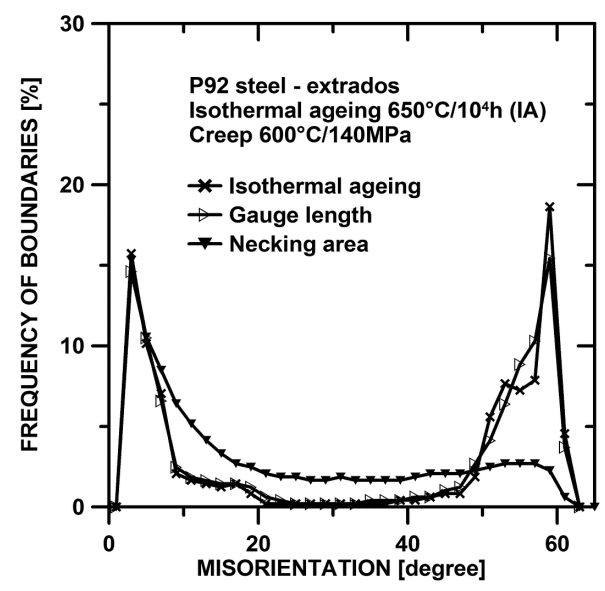

Fig. 7. Frequency of boundaries in the extrados part of bend after isothermal ageing at $650^{\circ} \mathrm{C} / 10^{4} \mathrm{~h}$ and subsequently tested at $600{ }^{\circ} \mathrm{C}$.

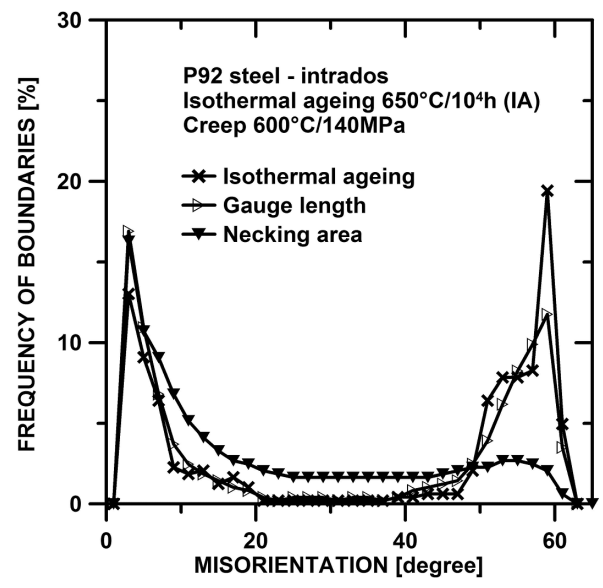

Fig. 8. Frequency of boundaries in the intrados part of bend after isothermal ageing at $650{ }^{\circ} \mathrm{C} / 10^{4} \mathrm{~h}$ and subsequently tested at $600{ }^{\circ} \mathrm{C}$.

gauge length of creep specimens the slight decrease in a number of boundaries with misorientation near $60^{\circ}$ in comparison with isothermally aged state can be observed. The significant changes in the misorientation distribution were found in the necking area of both extrados and intrados parts of the bend where the group of boundaries with misorientation $50-61^{\circ}$ was significantly reduced.

Microstructure characteristics of straight pipe and the bend exhibit similar tendency: coarsening in the gauge length and reduction of interboundary spacing in the necking area of isothermally aged states. Nevertheless, martensitic microstructure seems to be less stabile in the extrados and intrados of bend. It means that martensitic microstructure of bend is more sensitive to strain than microstructure in the straight part of pipe. We can speculate that stability of martensite microstructure in the bend is probably influenced either by more pronounced formation of the Laves phase weakening solid solution strengthening or by changes in pinning effect of MX carbonitrides in comparison with 
straight pipe. This may be supported by observation that interboundary spacing and misorientation distribution in particular in the necking area of extrados and intrados aged at $650^{\circ} \mathrm{C} / 10^{4} \mathrm{~h}$ are more similar to the microstructure characteristics of initial state processed by isothermal ageing at $650{ }^{\circ} \mathrm{C} / 2 \times 10^{4} \mathrm{~h}$ than those aged for shorter time of about $10^{4} \mathrm{~h}$.

\section{Conclusions}

Hot bending and long-term isothermal ageing together with hot bending have detrimental effect on creep resistance and led to larger strain to fracture.

Long-term isothermal ageing at $650^{\circ} \mathrm{C}$ has negligible effect on interboundary spacing. However, stability of microstructure is slightly deteriorated in the initial state and significantly in the state treated by longterm isothermal ageing and hot bending during creep deformation.

\section{Acknowledgments}

Financial support for this work was provided by the Technology Agency of the Czech Republic under Grant No. TA02010260.

\section{References}

[1] A. Strang, V. Vodarek, Mater. Sci. Technol. 12, 552 (1996).
[2] A. Orlova, J. Bursik, K. Kucharova, V. Sklenicka, Mater. Sci. Eng. A 245, 39 (1998).

[3] M. Maile, Int. J. Press. Vessels Piping 84, 62 (2007).

[4] C.G. Panait, A. Zielinska-Lipiec, T. Koziel, A. Czyrska-Filemonowicz, A.-F. Gourgues-Lorenzon, W. Bendick, Mater. Sci. Eng. A 527, 4062 (2010).

[5] R. Agamennone, W. Blum, C. Gupta, J.K. Chakravartty, Acta Mater. 54, 3003 (2006).

[6] G.V. Kurdjumov, G. Sachs, Z. Phys. 64, 325 (1930).

[7] Z. Nishiyama, Sci. Rep. Tohoku Imp. Univ. 23, 637 (1934).

[8] B. Sonderegger, S. Mitsche, H. Cerjak, Mater. Sci. Eng. A 481-482, 466 (2008).

[9] M. Svobodova, J. Cmakal, L. Horvath, T. Chmela, V. Sklenicka, in: Proc. 19th Int. Conf. on Metallurgy and Materials (Metal 2010), Tanger Ltd., Ostrava (Czech Republic), 2010, p. 374.

[10] V. Sklenicka, K. Kucharova, M. Svoboda, L. Kloc, J. Bursik, A. Kroupa, Mater. Charact. 51, 35 (2003).

[11] J.S. Lee, H.G. Armaki, K. Maruyama, T. Muraki, H. Asohi, Mater. Sci. Eng. A 428, 270 (2006).

[12] V. Sklenicka, K. Kucharova, M. Svoboda, A. Kroupa, J. Cmakal, Mater. Sci. Forum 654-656, 504 (2010).

[13] J. Hald, Int. J. Press. Vess. Pip. 85, 30 (2008).

[14] K. Sawada, K. Kubo, F. Abe, Mater. Sci. Eng. A 319-321, 784 (2001). 